Article

\title{
The Importance of $\mathrm{CH} \cdots X(X=\mathrm{O}, \pi)$ Interaction of a New Mixed Ligand Cu(II) Coordination Polymer: Structure, Hirshfeld Surface and Theoretical Studies
}

\author{
Saikat Kumar Seth \\ Department of Physics, Jadavpur University, Kolkata 700032, India; saikatim@yahoo.co.in or \\ skseth@phys.jdvu.ac.in
}

Received: 22 October 2018; Accepted: 5 December 2018; Published: 7 December 2018

\begin{abstract}
In this study, a new equimolar (1:1:1) mixed ligand $\mathrm{Cu}(\mathrm{II})$ polymer, $[\mathrm{Cu}(\mathrm{IDA})(\operatorname{ImP})]_{\mathrm{n}}(\mathbf{1})$ with iminodiacetato (IDA) and imidazo[1,2-a]-pyridine (ImP) was synthesized and characterized by single crystal X-ray diffraction analysis. X-ray crystallography reveals that compound (1) consists of polymeric zigzag chain along [010] the carboxylate carbonyl oxygen atom by two-fold symmetry screw axis. The solid-state structure is stabilized through $\mathrm{C}-\mathrm{H} \cdots \mathrm{O}$ hydrogen bonds and $\mathrm{C}-\mathrm{H} \cdots \pi$ interactions that lead the molecules to generate two-dimensional supramolecular assemblies. The intricate combinations of hydrogen bonds and $\mathrm{C}-\mathrm{H} \cdots \pi$ interactions are fully described along with computational studies. A thorough analysis of Hirshfeld surface and fingerprint plots elegantly quantify the interactions involved within the structure. The binding energies associated with the noncovalent interactions observed in the crystal structure and the interplay between them were calculated using theoretical DFT calculations. Weak noncovalent interactions were analyzed and characterized using Bader's theory of "atoms-in-molecules" (AIM). Finally, the solid-state supramolecular assembly was characterized by the "Noncovalent Interaction" (NCI) plot index.
\end{abstract}

Keywords: $\mathrm{Cu}$ (II)-IDA polymer; crystal structure; noncovalent interaction; Hirshfeld surface; density functional theory(DFT); atoms-in-molecules (AIM); noncovalent interaction (NCI) plot

\section{Introduction}

Coordination polymers (CPs) and/or metal-organic framework (MOFs) [1-3] represent multi-dimensional periodic structures of metal ions that are interconnected by organic bridging ligands, and have attracted great interest from scientists in the fields of crystal engineering, materials science, and supramolecular chemistry [4,5]. The rational design of CPs has increased significantly, owing to their fascinating structural architectures and their emerging application areas, including gas adsorption/separation, catalysis, magnetism, luminescence, sensors, etc. [6-9]. The most effective route to construct $\mathrm{CPs}$ is to use metal ions with mixed bridging ligands, especially with the bridging ligands containing $\mathrm{O} / \mathrm{N}$ atoms [10-12]. In the construction of $\mathrm{CPs}$, carboxylates and $\mathrm{N}$-donor ligands have been widely chosen [13-15] as building blocks mainly due to two aspects: (i) They can exhibit rich coordination modes and (ii) they can participate in hydrogen bonding interactions by acting as donors and/or acceptors. The rational design of CPs is the control of linkage between the metal ions that allows the construction of particular structural motifs and the chemical properties of the crystalline solids $[16,17]$. Though there are suitable ligands and metal ions to obtain CPs, it is still a prodigious task to predict the final structure, depending on reaction conditions in the self-assembly $[18,19]$. The interconnectivity of organic spacers and the presence of ancillary ligands plays a substantial role in estimating the final structures $[18,20]$. Moreover, CPs can organize their final solid-state structure by employing a variety of non-bonded interactions such as electrostatic 
attraction, hydrogen bonding, interactions involving $\pi$-ring [21-24]. In this respect, C-H $\cdots \pi$ [25-27], $\pi$-stacking [28-31], anion $\cdots \pi[32-35]$ and lone pair $\cdots \pi[36,37]$ interactions have been successfully used in building supramolecular networks [38]. A proper understanding of these forces is extremely significant, since the problem of prediction is often limited to the recognition patterns or supramolecular synthons of different functional groups. The control of the topology of crystal packing through covalent and noncovalent interactions is the main goal of crystal engineering. Therefore, proper understanding of noncovalent forces is crucial to design and predict new supramolecular entities based on mono-dimensional coordination polymers.

Keeping this in mind, a new $\mathrm{Cu}(\mathrm{II})$ polymer $[\mathrm{Cu}(\mathrm{IDA})(\mathrm{ImP})]_{\mathrm{n}}(\mathbf{1})\left(\mathrm{H}_{2} \mathrm{IDA}=\right.$ Iminodiacetic acid and $\operatorname{ImP}=$ Imidazo[1-a]-pyridine]), has been synthesized (see Scheme 1) and characterized by single crystal X-ray diffraction. The title 1D polymer is stabilized through hydrogen bonds and $\mathrm{C}-\mathrm{H} \cdots \pi$ interaction in building 2D layered structures. The structural descriptions have been corroborated with theoretical calculations. The weak noncovalent interactions observed in the title polymer have been analyzed both energetically and using Bader's theory of "atoms in molecules" by means of Density Functional theory (DFT) calculations.

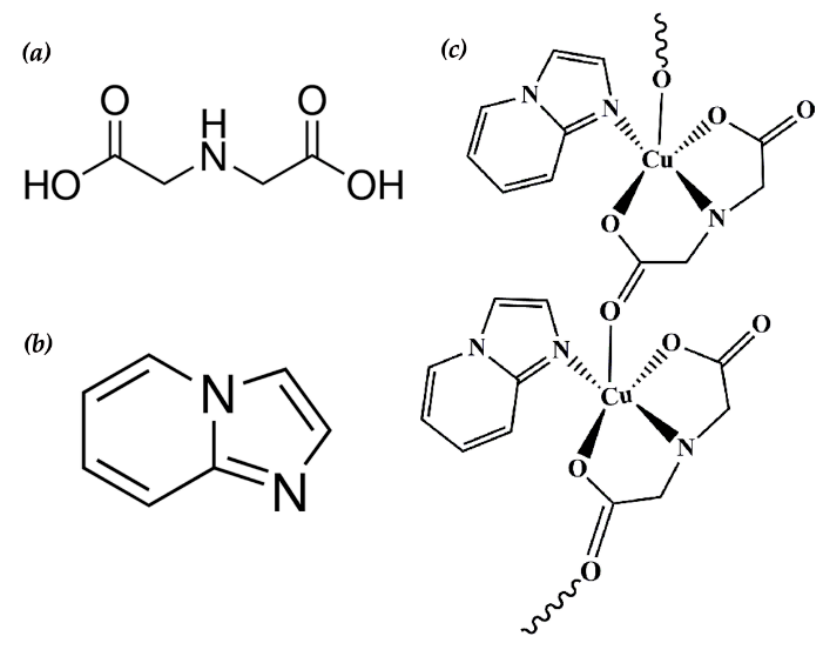

Scheme 1. Chemical diagrams of the primary ligand (a), secondary ligand (b) and the title metal compound (c).

\section{Materials and Methods}

\subsection{Materials and Measurements}

The reaction was carried out in aerobic conditions and in an aqueous medium. Iminodiacetic acid (Aldrich, St. Louis, Missouri, United States), basic copper(II) nitrate trihydrate (Sigma, St. Louis, Missouri, United States), and Imidazo[1,2-a]-pyridine (Aldrich, St. Louis, Missouri, United States) were used as received. Double distilled and then freshly boiled water was used throughout. IR spectra (KBr disk) was performed on a Perkin-Elmer RXI FT-IR spectrophotometer (Perkin Elmer Inc.,Waltham, MA, USA). Elemental analysis was carried out on a Perkin-Elmer 240C elemental analyzer.

\subsection{Synthesis}

Basic copper(II) nitrate trihydrate [purum $\geq 98.0 \%$ ], $\mathrm{Cu}\left(\mathrm{NO}_{3}\right)_{2} \cdot 3 \mathrm{H}_{2} \mathrm{O}(0.483 \mathrm{~g}, 2.0 \mathrm{mmol})$, was reacted with iminodiacetic acid [purum $\geq 98.0 \%$ ] $(0.266 \mathrm{~g}, 2.0 \mathrm{mmol})$ in water $(25 \mathrm{~mL})$ nearly at $70{ }^{\circ} \mathrm{C}$ until a clear solution resulted in an open glassware. A warm $\left(\sim 40^{\circ} \mathrm{C}\right)$ aqueous solution $(20 \mathrm{~mL})$ of Imidazo[1,2-a]-pyridine [purum $\sim 99.0 \%$ ] $(0.236 \mathrm{~g}, 2.0 \mathrm{mmol})$ was then added dropwise to the above solution with continuous stirring for about an hour at normal laboratory temperature $\left(\sim 30^{\circ} \mathrm{C}\right)$. The solution mixture was then left undisturbed for a few days when block shaped; light blue crystals 
suitable for X-ray diffraction analysis were obtained. The crystals were collected by filtration, washed with cold water, and dried in air (yield $=60 \%$ ). Anal. Calcd. for $\mathrm{C}_{11} \mathrm{H}_{11} \mathrm{CuN}_{3} \mathrm{O}_{4}\left(M_{W}=312.74\right)$ : $\mathrm{C}$, 42.24; H, 3.54; N, 13.43\%. Found: C, 46.21; H, 3.51; N, 13.46\%. FT-IR ( $\left.\mathrm{cm}^{-1}\right): 3185$ (b), 3120 (s), 3081 (s), 3046 (s), 2922 (b), 1657 (s), 1615 (s), 1503 (s), 1435 (s), 1411 (s), 1375 (s), 1338 (s), 1315 (s), 1288 (s), 1238 (s), $1164(\mathrm{~s}), 1127(\mathrm{~s}), 1109$ (s), 1026 (s), 1011 (s), 959 (s), 905 (s), 870 (s), 788 (s), $762(\mathrm{~s}), 747$ (s), 727 (s), $663(\mathrm{~s}), 637(\mathrm{~s}), 608(\mathrm{~s}), 580(\mathrm{~s}), 556(\mathrm{~s}), 506(\mathrm{~s}), 456(\mathrm{~s})$.

\subsection{X-ray Crystallography Study}

The single crystal X-ray diffraction intensity data of the title compound was collected at 293(2) K using a Bruker APEX-II CCD diffractometer equipped with graphite monochromated MoK $\alpha$ radiation $(\lambda=0.71073 \AA)$. Data reduction was carried out using the Bruker SAINT [39] program and an empirical absorption correction was applied based on the multi-scan method [40]. The structure of the title compound was solved by the direct method and refined by the full-matrix least-square technique on $\mathrm{F}^{2}$ using the programs SHELXS-14 [41] and SHELXL-18 [42], respectively. All the hydrogen atoms were placed at their geometrically idealized positions and refined isotropically. All calculations were carried out using the WinGX system V2014.1 [43] and PLATON [44]. A summary of crystal data and relevant refinement parameters are given in Table 1. CCDC 1,868,166 contain the supplementary crystallographic data of this paper.

Table 1. Crystal data and structure refinement parameters for title compound.

\begin{tabular}{|c|c|}
\hline Empirical formula & $\left(\mathrm{C}_{11} \mathrm{H}_{11} \mathrm{CuN}_{3} \mathrm{O}_{4}\right)_{\mathrm{n}}$ \\
\hline Formula weight & 312.77 \\
\hline Temperature & 293(2) K \\
\hline Wavelength & $0.71073 \AA$ \\
\hline Crystal system, space group & Monoclinic, $\mathrm{P} 2_{1}$ \\
\hline Unit cell dimensions & $\begin{array}{c}\mathrm{a}=8.178(3) \AA ; \alpha=90^{\circ} \\
\mathrm{b}=7.155(2) \AA ; \beta=102.324(3)^{\circ} \\
\mathrm{c}=10.118(3) \AA ; \gamma=90^{\circ}\end{array}$ \\
\hline Volume & $578.5(3) \AA^{3}$ \\
\hline Z, Calculated density & $2,1.796 \mathrm{Mg} / \mathrm{m}^{3}$ \\
\hline Absorption coefficient & $1.902 \mathrm{~mm}^{-1}$ \\
\hline $\mathrm{F}(000)$ & 318 \\
\hline Crystal size & $0.12 \times 0.07 \times 0.04 \mathrm{~mm}$ \\
\hline$\theta$ range for data collection & 2.060 to $24.998^{\circ}$ \\
\hline Limiting indices & $-9 \leq \mathrm{h} \leq 9,-8 \leq \mathrm{k} \leq 8,-11 \leq 1 \leq 12$ \\
\hline Reflections collected/unique & $5093 / 1883[\mathrm{R}(\mathrm{int})=0.0244]$ \\
\hline Completeness to $\theta$ & $100.0 \%$ \\
\hline Absorption correction & Semi-empirical from equivalents \\
\hline Max. and min. transmission & 0.93 and 0.85 \\
\hline Refinement method & Full-matrix least-squares on $|\mathrm{F}|^{2}$ \\
\hline Data/parameters & $1883 / 174$ \\
\hline Goodness-of-fit on $\mathrm{F}^{2}$ & 1.092 \\
\hline Flack parameter & $0.051(18)$ \\
\hline Absolute structure parameter & $0.051(18)$ \\
\hline Extinction coefficient & $0.012(2)$ \\
\hline Final $R$ indices $[I>2 \sigma(I)]$ & $\mathrm{R}_{1}=0.0186, w \mathrm{R}_{2}=0.0489$ \\
\hline $\mathrm{R}$ indices (all data) & $\mathrm{R}_{1}=0.0191, w \mathrm{R}_{2}=0.0496$ \\
\hline Largest diff. peak and hole & 0.192 and $-0.181 \mathrm{e} \cdot \AA^{-3}$ \\
\hline
\end{tabular}

\subsection{Hirshfeld Surface Analysis}

The molecular Hirshfeld surface [45-49] is created based on the electron distribution of a molecule and has been calculated as the sum of spherical atom electron densities [50,51]. For a given crystal structure and set of spherical atomic electron densities, the Hirshfeld surface is unique [52]. The 
normalized contact distance $\left(d_{\text {norm }}\right)$ calculated by Equation (1) was used to locate both inner and outer intermolecular interactions simultaneously on a single Hirshfeld surface [45]. Where, $d_{e}$ is the distance from the point to the nearest nucleus external to the surface, $d_{i}$ is the distance to the nearest nucleus internal to the surface; $r_{i}^{v d w}$ and $r_{e}^{v d w}$ are the internal and external van der Walls (vdW) radii of the two atoms to the surface, respectively. The 2D fingerprint plot provides a summary of intermolecular contacts in the crystal [52-56]. The Hirshfeld surface presented here was generated using Crystal Explorer 3.1. [57].

$$
d_{n o r m}=\frac{d_{i}-r_{i}^{v d w}}{r_{i}^{v d w}}+\frac{d_{e}-r_{e}^{v d w}}{r_{e}^{v d w}}
$$

\subsection{Theoretical Methods}

The energies of the title compound included in this study were performed using Gaussian 09 calculation package [58] at the B3LYP level with a large basis set $6-311++G(d, p)$. The visualization of the results is accomplished with GaussView 5.0. The B3LYP method of DFT is quite reliable for the prediction of geometric and electronic properties of neutral [59] and charged species [60], ranging from simple molecular to polymer structures [61]. For the theoretical analysis of the noncovalent interactions present in the solid state, we have used crystallographic coordinates. The Bader's "Atoms in molecules" theory [62] has been used to analyze the interactions studied herein by means of the AIMall calculation package [63]. The topological properties of the charge density $(\rho(\mathrm{r}))$ characterized by their critical points (CPs) and its Laplacian, which is expressed in terms of $L(r)=-\nabla^{2}(\rho(r))$, were calculated using the Atom In Molecule (AIM) theory [64]. It is noted that electron density is concentrated where $\nabla^{2}$ $(\rho(\mathrm{r}))<0$ and it is depleted where $\nabla^{2}(\rho(\mathrm{r}))>0$. The calculations for the wave function analysis have been performed using Gaussian09 calculation package [58]. The NCI is a visualization index based on the electron density and its derivatives [65]. Since the noncovalent interactions are represented using isosurfaces instead of critical points, it enables their efficient visualization and identification. The isosurfaces may correspond to either favorable or unfavorable interactions, which are differentiated by the signs of the second density Hessian eigenvalues and defined by the isosurface color. NCI plot facilitates the assessment of host-guest complementarity and the extent to which weak interactions stabilize a complex. However, the information delivered by NCI plots is fundamentally qualitative, i.e., which molecular regions are interacting. The color scheme is a red-yellow-green-blue scale with red for $\rho^{+}$cut (repulsive) and blue for $\rho^{-}$cut (attractive). Yellow and green surfaces correspond to weak repulsive and weak attractive interactions, respectively [65].

\section{Results and Discussion}

\subsection{Structural Description}

Crystal structure analysis reveals that compound (1) is a one-dimensional metal-organic coordination polymer constructed from $\mathrm{Cu}$ (II) ion, iminodiacetic acid, and imidazo[1,2-a]-pyridine. An ORTEP drawing is presented in Figure 1 with atom numbering scheme. Two carboxylate oxygen atoms and one nitrogen atom of the IDA ligand and one nitrogen atom of the ImP molecule define a distorted square base coordination geometry. The $\mathrm{Cu}(\mathrm{II})$ atom is displaced only 0.051(1) $\AA$ from the mean plane $\mathrm{P}(1)$ generated through the atoms (O1-O4-N1-N2). The $\mathrm{Cu}(\mathrm{II})$ is displaced towards the fifth donor atom $\mathrm{O}^{\mathrm{i}}$ (symmetry code $\mathrm{i}=2-\mathrm{x}, 1 / 2+\mathrm{y}, 1-\mathrm{z}$ ) of the adjacent IDA ligand that is related to the former molecule by two-fold symmetry screw axis. The $\mathrm{Cu}(\mathrm{II})$ atom lies in a rather common distorted square base pyramidal environment of the type $(4+1)$ and therefore, the $\mathrm{Cu}-\mathrm{O} 2^{\mathrm{i}}$ bond-length is typically longer in comparison to other four coordination bonds (Table S1). The imidazo[1,2-a]-pyridine is strictly planar and $\mathrm{Cu}(\mathrm{II})$ atom lies $0.082 \AA$ out from this plane $\mathrm{P}(2)$ that defines a dihedral angle of $36.29^{\circ}$ with plane $\mathrm{P}(1)$. The percentage of trigonal distortion of the square pyramidal stereochemistry [66], obtained from trans angles $\theta=\mathrm{N}(1)-\mathrm{Cu}(1)-\mathrm{N}(2)$ and $\rho=\mathrm{O}(1)-\mathrm{Cu}(1)-\mathrm{O}(4)$, is $\tau=100(\theta-\rho) / 60=19.5$. This value is comparable with the reported analogous 
five-coordinated compounds [Cu(IDA) (4-aminopyridine) $\left.\left(\mathrm{H}_{2} \mathrm{O}\right)\right]$ [36] and [Cu(IDA)(5MeImH) [67] and significantly higher than [[Cu(MIDA) $(\mathrm{ImH})][68]$ and low value compare to the compound $\left[\mathrm{Cu}(\mathrm{IDA})(\mathrm{ImH})\left(\mathrm{H}_{2} \mathrm{O}\right)\right] \cdot \mathrm{H}_{2} \mathrm{O}$ [69]. Again, the dihedral angle between the mean planes for the two $\mathrm{Cu}$-glycinate five-membered rings $\left(\varphi=22.30^{\circ}\right)$ shows almost coplanar conformation of the five-membered chelate rings of $\mathrm{Cu}$ (IDA) moiety. This structural feature agrees well with the nearly coplanar chelate rings in the $\mathrm{Cu}(\mathrm{IDA})$ moiety of the 1:1:1 $\mathrm{Cu} / \mathrm{IDA} / \mathrm{N}$-heterocyclic donor compounds reported earlier $[36,67,68,70]$.

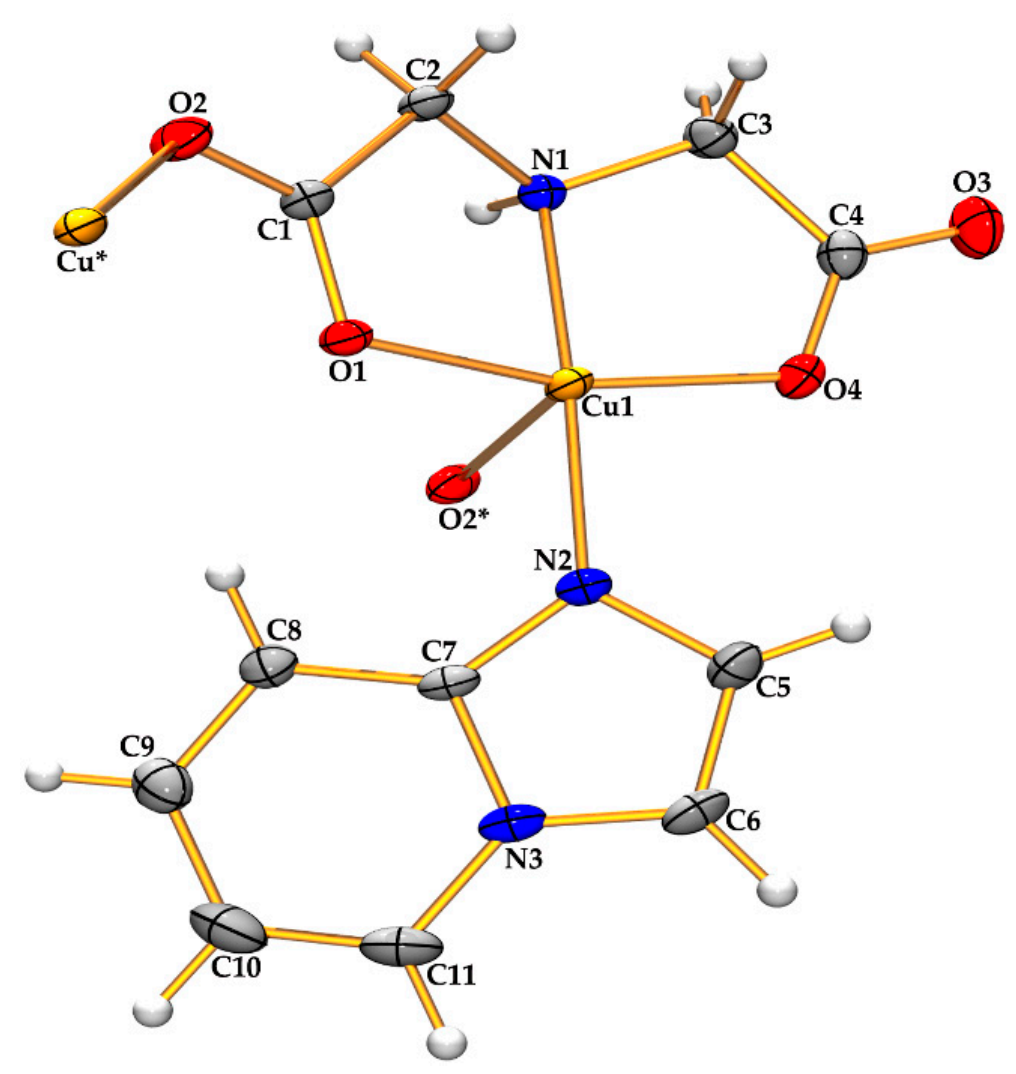

Figure 1. An ORTEP view (ellipsoids of thermal oscillations with $30 \%$ probabilities) with atom numbering scheme of compound (1). The atoms that are labelled with $\left({ }^{*}\right)$ are generated through symmetry operation $(2-x, 1 / 2+y, 1-z)$.

In compound (1), the molecules are propagating along [010] direction through coordination-bonding mode and generating a 1-D coordination polymer (See Figure 2). The solid-state structure of $(\mathbf{1})$ comprises a combination of $\mathrm{N}-\mathrm{H} \cdots \mathrm{O}, \mathrm{C}-\mathrm{H} \cdots \mathrm{O}$ hydrogen bonds and $\mathrm{C}-\mathrm{H} \cdots \pi$ interactions (Table 2). The $[\mathrm{Cu}(\mathrm{IDA})(\mathrm{ImP})]$ units are interconnected to generate the polymeric chain through the coordination bonding in between parent $\mathrm{Cu}(1)$ atom and carbonyl oxygen atom $\mathrm{O}(2)$ of the partner molecule (Figure 2). The 1D polymeric chain network is further strengthened by $\mathrm{N}-\mathrm{H} \cdots \mathrm{O}$ hydrogen bonding contacts, where the nitrogen atom $\mathrm{N}(1)$ acts as a donor to the carboxylate oxygen atom $\mathrm{O}(1)$ in the molecule at $(2-\mathrm{x}, 1 / 2+\mathrm{y}, 1-\mathrm{z})$ (See Figure S1). The ring carbon atom $\mathrm{C}(8)$ acted as a donor to the carbonyl oxygen atom $\mathrm{O}(3)$ of the parallel chain structure in the molecule at $(1+\mathrm{x}, \mathrm{y}, \mathrm{z})$, thereby generating a two-dimensional layer network in (110) plane (Figure 2). 


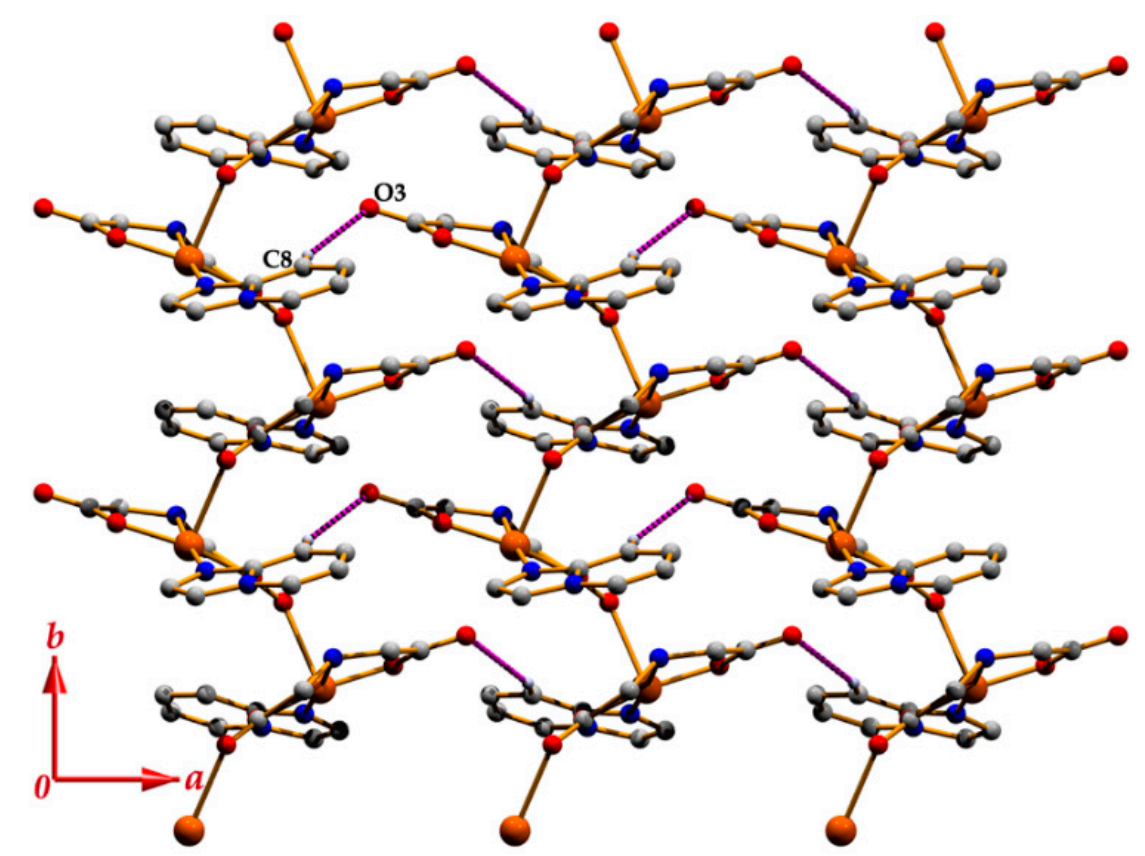

Figure 2. 1D polymeric chains are interconnected through $\mathrm{C}-\mathrm{H} \cdots \mathrm{O}$ hydrogen bond to generate a layered assembly in (110) plane.

In another substructure, the molecules are self-assembled through two $\mathrm{C}-\mathrm{H} \cdots \mathrm{O}$ bonding interactions. Interconnection in between carbon atoms $C(8)$ and $C(6)$ with carbonyl oxygen atoms $\mathrm{O}(3)$ and $\mathrm{O}(2)$ in the molecule at $(1+\mathrm{x}, \mathrm{y}, \mathrm{z})$ and $(\mathrm{x}, \mathrm{y}, 1+\mathrm{z})$ respectively, leads the molecules to generate $\mathrm{a}$ two-dimensional supramolecular network in (101) plane (Figure 3).



Figure 3. Perspective view of the supramolecular network generated through hydrogen bonds. 
Table 2. Relevant Hydrogen Bonding Parameters in (1).

\begin{tabular}{|c|c|c|c|c|c|}
\hline D-H $\cdots A$ & D-H & $\mathrm{H} \cdots \mathrm{A}$ & $\mathrm{D} \cdots \mathrm{A}$ & D-H $\cdots A$ & Symmetry \\
\hline $\mathrm{N}(1)-\mathrm{H}(1) \cdots \mathrm{O}(1)$ & 0.98 & 2.05 & $2.910(4)$ & 146 & $2-x, 1 / 2+y, 1-z$ \\
\hline $\mathrm{C}(2)-\mathrm{H}(2 \mathrm{~B}) \cdots \mathrm{O}(3)$ & 0.97 & 2.57 & $3.057(5)$ & 111 & $1-x, 1 / 2+y, 1-z$ \\
\hline $\mathrm{C}(6)-\mathrm{H}(6) \cdots \mathrm{O}(2)$ & 0.93 & 2.41 & $3.175(4)$ & 139 & $x, y, 1+z$ \\
\hline $\mathrm{C}(8)-\mathrm{H}(8) \cdots \mathrm{O}(1)$ & 0.93 & 2.49 & $3.089(4)$ & 122 & - - \\
\hline $\mathrm{C}(8)-\mathrm{H}(8) \cdots \mathrm{O}(3)$ & 0.93 & 2.59 & $3.405(5)$ & 146 & $1+x, y, z$ \\
\hline $\mathrm{C}(6)-\mathrm{H}(6) \cdots \mathrm{Cg}(4)$ & 0.93 & 2.94 & $3.424(4)$ & 114 & $2-x, 1 / 2+y, 2-z$ \\
\hline
\end{tabular}

$\mathrm{Cg}(4)$ is the centroid of the (N3/C7-C11) ring.

In the final substructure, the 1-D parallel chain is juxtaposed through self-complementary $\mathrm{C}-\mathrm{H} \cdots \pi$ interactions. The carbon atom $\mathrm{C}(6)$ in the molecule at $(x, y, z)$ acts as a donor to the $\pi$-cloud of the pyridine ring at $(2-x, 1 / 2+y, 2-z)$ (Table 2); therefore generating a two-dimensional supramolecular self-assembled structure in (011) plane (Figure 4). Consequently, this entire assembly as a whole produces a supramolecular combination of $\mathrm{C}-\mathrm{H} \cdots \pi$ interactions that illustrates the occurrence of a self-assembled two-dimensional supramolecular layered structure of a polymeric compound.

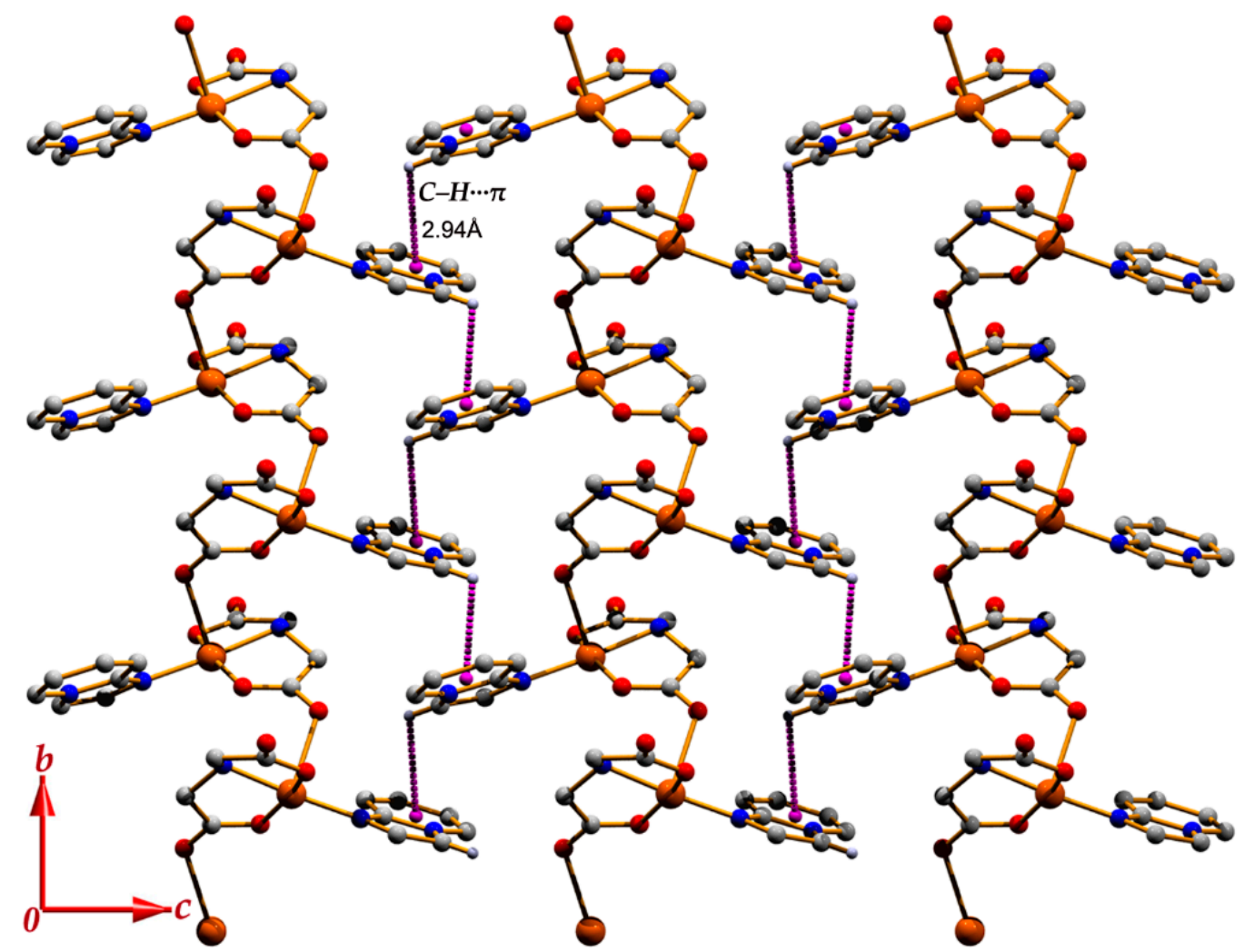

Figure 4. Formation of supramolecular layer network in (011) plane.

\subsection{Hirshfeld Surface}

The Hirshfeld surface [45-49] emerged from a unique attempt to define the space occupied by a molecule in a crystal to partition the crystal electron density into molecular fragments [50,51]. In this study, the contacts that are responsible in the crystal packing are estimated with respect to their contribution to the crystal structure. The Hirshfeld surface of the title compound is illustrated in Figure 5 showing surfaces that have been mapped over $d_{\text {norm }}$ and $d_{e}$. The information concerning intermolecular interactions that are presented in Table 2 are noticeable by the spots on the $d_{\text {norm }}$ surface. The large circular depression (deep red) on the $d_{n o r m}$ surface, which is evident just above the metal ion, designate the $\mathrm{Cu} \cdots \mathrm{O}$ bonding contacts. Other light-colored depressions on the $d_{n o r m}$ 
surface are an indicator of weaker contacts. Fingerprint plots are the key tools for the calculation of the density of intermolecular contacts present in a crystal and can be decomposed to quantify individual contributions of intermolecular interactions related to each structure. The combination of $d_{e}$ and $d_{i}$ in the form of a 2D fingerprint plot [52-56] provides a summary of the intermolecular contacts in the crystal, where one molecule acts as a donor $\left(d_{e}>d_{i}\right)$ and other as an acceptor $\left(d_{i}>d_{e}\right)$. The $\mathrm{Cu} \cdots \mathrm{O} / \mathrm{O} \cdots \mathrm{Cu}$ contacts are evidenced by two distinct spikes in the $\left(d_{i}, d_{e}\right)$ region (1.262 $\AA, 1.171 \AA$ ) of the fingerprint plot that comprised $4.8 \%$ of the total Hirshfeld surface area of the molecule (Figure S2). The $\mathrm{N} \cdots \mathrm{H} / \mathrm{H} \cdots \mathrm{N}$ contacts are evidenced by the scattered points on the fingerprint plot (Figure S2), where $\mathrm{N} \cdots \mathrm{H}$ interaction contributed more $\left[2.4 \% ;\left(d_{i}=1.818, d_{e}=1.242\right)\right]$ compared to the $\mathrm{H} \cdots \mathrm{N}$ counterpart $\left.\left[1.8 \% ; d_{e}=1.188, d_{i}=1.242\right)\right]$. The $\mathrm{O} \cdots \mathrm{H} / \mathrm{H} \cdots \mathrm{O}$ interactions contributed $29.6 \%$ and are evidenced by the distinct spikes in the $\left(d_{i}, d_{e}\right)$ region of $(1.171 \AA, 0.831 \AA)$ (Figure 6). The $\mathrm{C} \cdots \mathrm{H} / \mathrm{H} \cdots \mathrm{C}$ interactions appear as two spikes in the fingerprint plot, where the proportion of $\mathrm{C} \cdots \mathrm{H} / \mathrm{H} \cdots \mathrm{C}$ interactions comprise $18.4 \%$ of the total Hirshfeld surface area of (1). The C $\cdots \mathrm{H}$ interactions are represented by the spike in the bottom right region $\left(d_{i}=1.552 \AA, d_{e}=1.056 \AA\right)$, whereas the $\mathrm{H} \cdots \mathrm{C}$ spike is located at $\left(d_{e}=1.562 \AA, d_{i}=1.056 \AA\right)$ and comprises $10.7 \%$ and $7.7 \%$, respectively (Figure 6).
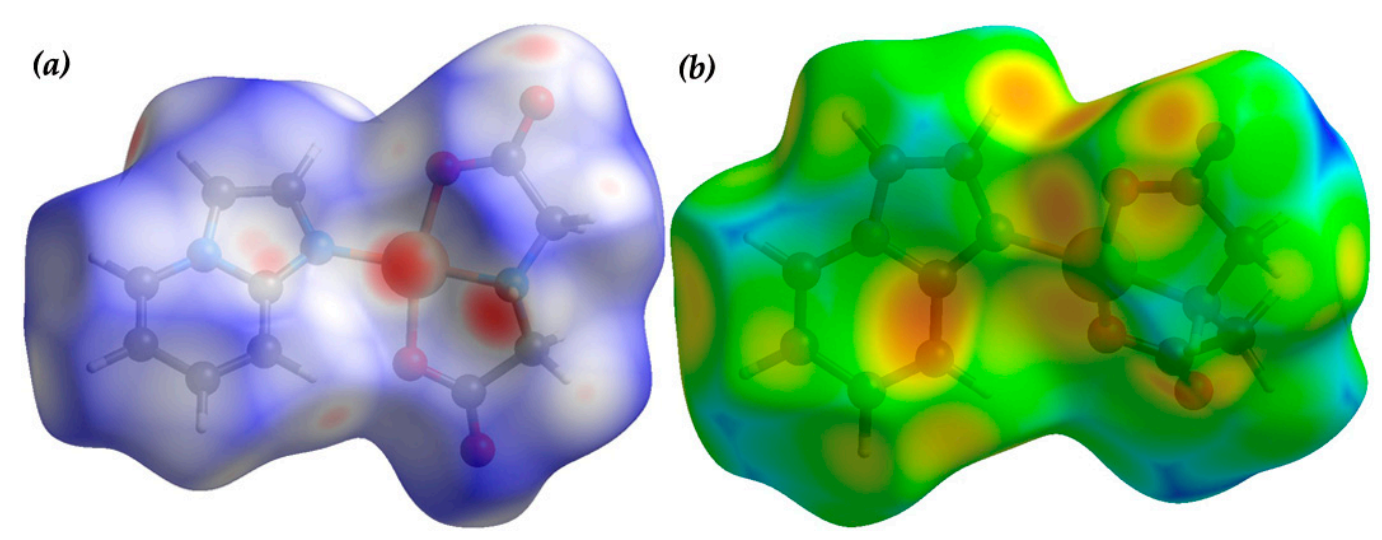

Figure 5. Hirshfeld surface of compound (1) mapped with $d_{\text {norm }}(\mathbf{a})$ and $d_{e}(\mathbf{b})$.

Apart from the hydrogen bonding contacts, the structure is stabilized through $\mathrm{C}-\mathrm{H} \cdots \pi$ interaction and is visible on the $d_{e}$ surface as well as in the fingerprint plot. The 'bright-orange' spot and consequently a large depression on the $d_{e}$ surface above the $\pi$-cloud of the aryl ring indicates the existence of a $\mathrm{C}-\mathrm{H} \cdots \pi$ interaction (Figure 5). Moreover, the $\mathrm{C}-\mathrm{H} \cdots \pi$ interaction is also evidenced by a pair of 'wings' in the fingerprint plot, where the left wing region $\left(d_{i}<d_{e}\right)$ correspond to the points on the surface around the $\mathrm{C}-\mathrm{H}$ donor and the right wing region $\left(d_{e}<d_{i}\right)$ corresponds to the points around the $\pi$-acceptor. From Hirshfeld surface calculations, it is not possible to individuate the $\mathrm{C} \cdots \mathrm{H} / \mathrm{H} \cdots \mathrm{C}$ contacts for hydrogen bond and $\mathrm{C}-\mathrm{H} \cdots \pi$ interactions. The decomposed $d_{\text {norm }}$ plots corresponding to each type of interactions involved within the structure are included in Figure S3. The decomposed fingerprint plots corresponding to various interactions that contributed more than $5 \%$ are included in Figure 6, whereas the others are included in Figure S1. A detailed analysis of intermolecular contacts reveals that the title compound comprises $\mathrm{C} \cdots \mathrm{O} / \mathrm{O} \cdots \mathrm{C}, \mathrm{C} \cdots \mathrm{N} / \mathrm{N} \cdots \mathrm{C}$ and $\mathrm{N} \cdots \mathrm{O} / \mathrm{O} \cdots \mathrm{N}$ contacts that comprised only $1.5 \%, 1.9 \%$ and $1.0 \%$, respectively (Figure S2). Significant molecular interactions of the title compound in terms of $\mathrm{O} \cdots \mathrm{O}$ and $\mathrm{C} \cdots \mathrm{C}$ contacts are reflected in the distribution of scattered points in the region of $\left(d_{i}=d_{e}=1.805 \AA\right)$ and $\left(d_{i}=d_{e}=1.813 \AA\right)$ respectively (Figure S2). Moreover, the distribution of scattered points in the fingerprint plot that spread only up to $\left(d_{i}=d_{e}=1.101 \AA\right)$ designate $\mathrm{H} \cdots \mathrm{H}$ contacts that comprises $33.9 \%$ (Figure 6) of the total Hirshfeld surface area of compound (1). 

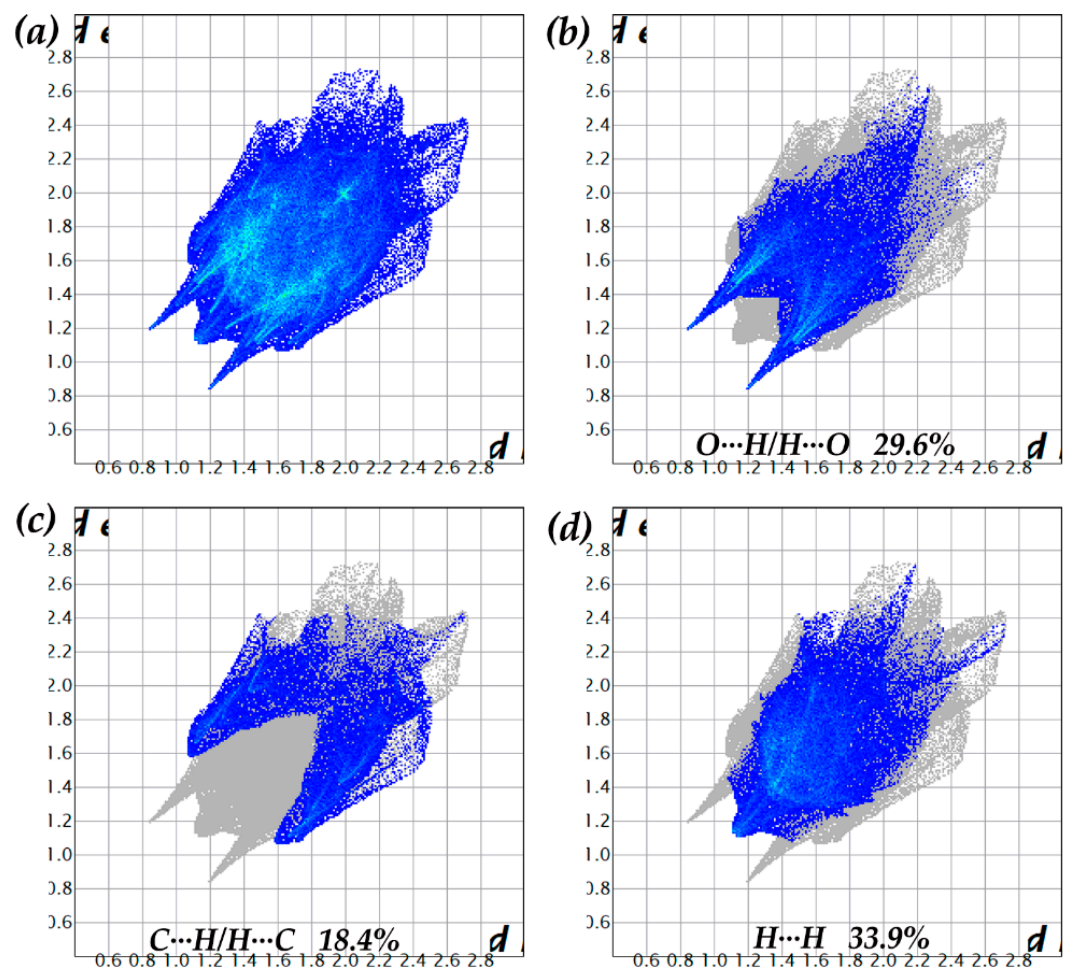

Figure 6. Fingerprint plots: Full (a) and resolved into $\mathrm{O} \cdots \mathrm{H} / \mathrm{H} \cdots \mathrm{O}(\mathbf{b}) ; \mathrm{C} \cdots \mathrm{H} / \mathrm{H} \cdots \mathrm{C}$ (c) and $\mathrm{H} \cdots \mathrm{H}$ (d) interactions showing percentages of contacts (more than 5\%) to the total Hirshfeld surface area of the molecules.

\subsection{Theoretical Calculations}

Computational studies are included herein to analyze the noncovalent interactions using theoretical DFT calculation. This study mainly focused on two issues: First, the energetic features of the interactions are studied and second, the interplay of noncovalent interactions are characterized by Bader's theory of "atoms-in-molecules" (AIM). The crystallographic coordinates have been used in the computational studies. To evaluate formation energies, few models were prepared following self-assembled X-ray structure (Figures 7 and 8). Following the X-ray fragment (Figure 7a), the imidazo[1,2-a]-pyridine moiety is simplified (see the black arrow in Figure $7 \mathrm{~b}$ ) to avoid the short contact in between the pyridine ring carbon atom and the carbonyl oxygen atom. In this model (model-1), the formation energy of the $\mathrm{C}-\mathrm{H} \cdots \mathrm{O}$ hydrogen bond is $\Delta \mathrm{E}_{1}=-5.6 \mathrm{Kcal} / \mathrm{mol}$. Following Figures 2 and 3, we are interested to evaluate the formation energy of the C8-H8 ‥O3 hydrogen bond. In model-2 (Figure 7c), it is observed that another pyridine ring carbon atom C9 is in contact with the carboxylate oxygen atom $\mathrm{O} 4$ (see red dotted line). Mutual interactions displayed the formation energy of $\Delta \mathrm{E}_{2}=-3.5 \mathrm{Kcal} / \mathrm{mol}$.

Again, following an X-ray structure (Figure 8a), we carried out formation energy of $\mathrm{C}-\mathrm{H} \cdots \pi$ interaction in some models; the results are included in Figure 8b-d. In model-3, we computed the interaction energy using two uncoordinated imidazo[1,2-a]-pyridine moieties (Figure 8b). As a result, the interaction energy is modest $\left(\Delta \mathrm{E}_{3}=-0.9 \mathrm{Kcal} / \mathrm{mol}\right)$. In another model, we analyzed the effect of metal coordination, including IDA moiety, keeping other imidazo[1,2-a]-pyridine moiety fixed (Figure 8c). As a result, the interaction energy increases to $\Delta \mathrm{E}_{4}=-2.2 \mathrm{Kcal} / \mathrm{mol}$, therefore confirming the reinforcement of the $\mathrm{C}-\mathrm{H} \cdots \pi$ interaction due to the metal coordinated moiety. In the fifth model, we studied the effect of the coordination mode in both moieties to analyze the strength of the interaction. It is expected to have a stronger effect on the strength of the interaction. As expected, the interaction energy of the theoretical model (Figure $8 \mathrm{~d}$ ) is $\Delta \mathrm{E}_{5}=-3.0 \mathrm{Kcal} / \mathrm{mol}$, which is much more favorable than $\Delta \mathrm{E}_{3}=-0.9 \mathrm{Kcal} / \mathrm{mol}$. 


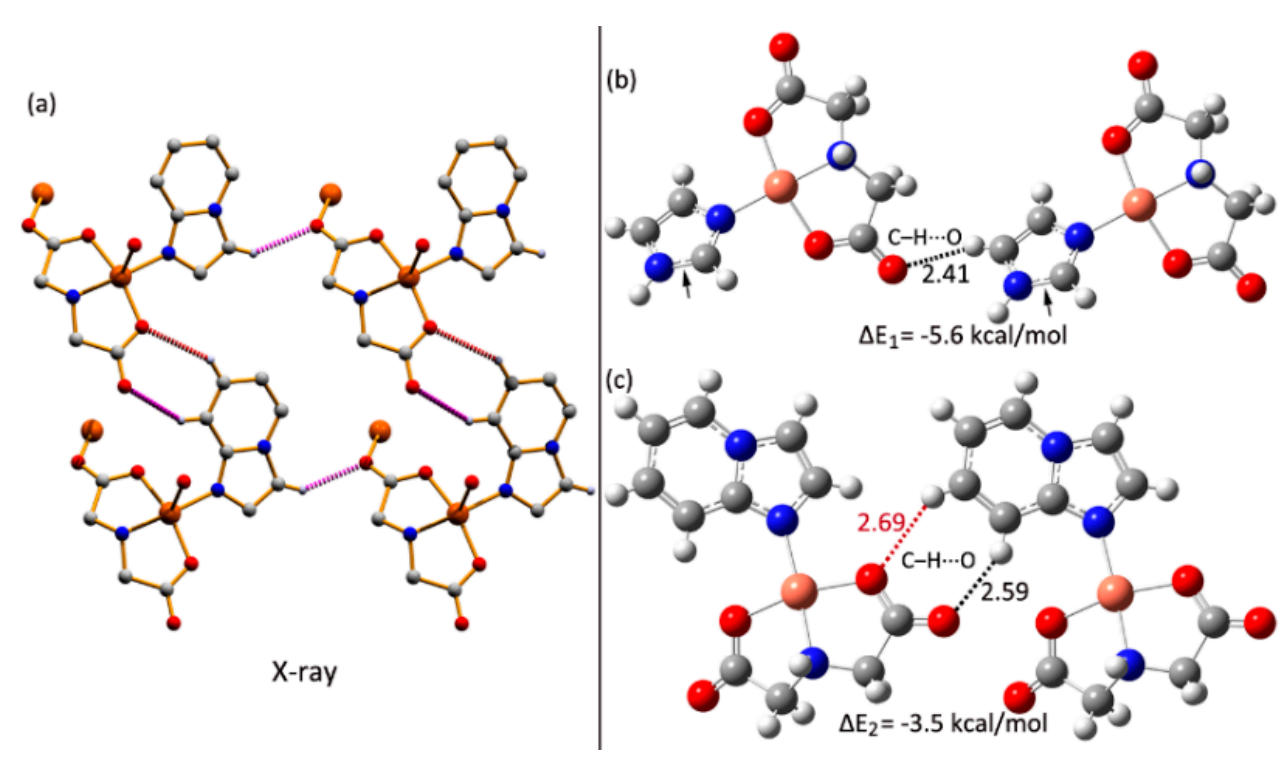

Figure 7. (a) X-ray fragment. $(\mathbf{b}, \mathbf{c})$ theoretical models used to estimate the formation energies.

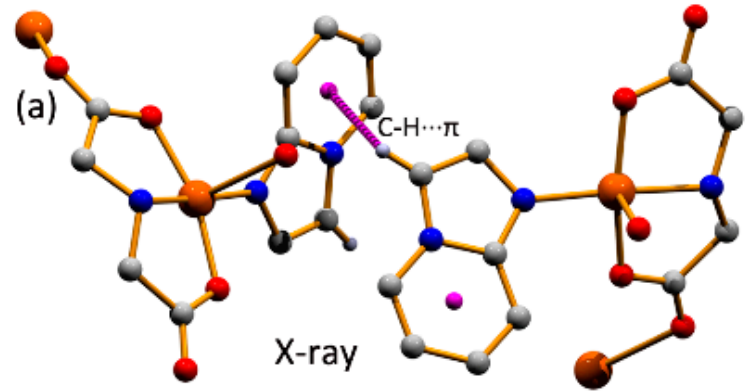

(b)

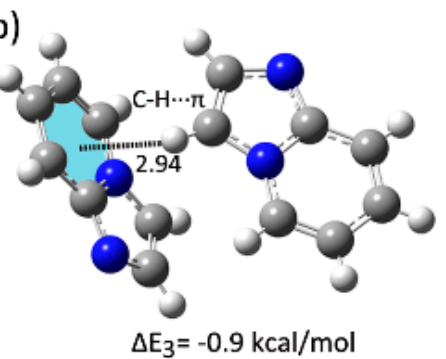

(c)
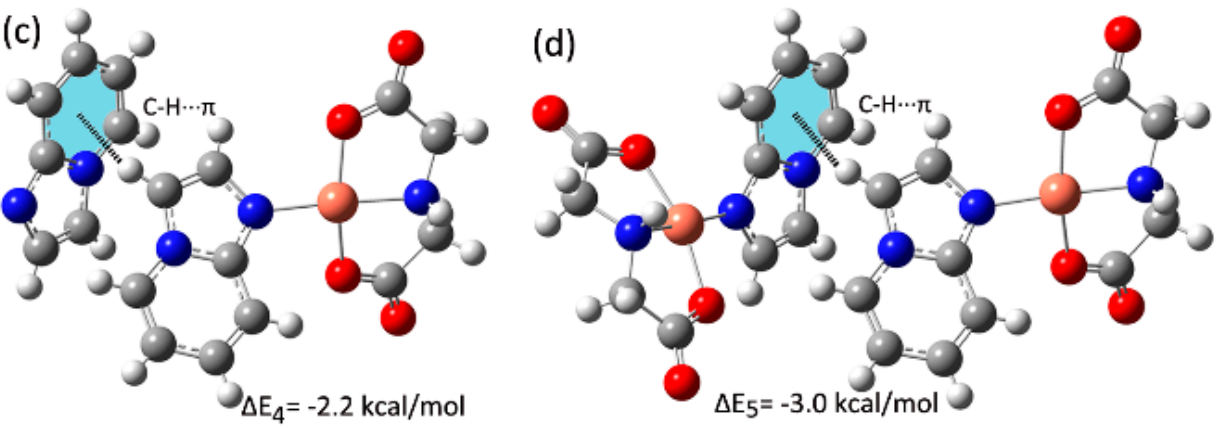

Figure 8. (a) X-ray fragment. (b-d) Theoretical models used to estimate the $\mathrm{C}-\mathrm{H} \cdots \pi$ interaction.

We performed the Bader's theory of atoms in molecules (AIM) analysis of compound (1) by using the models described above. The AIM analysis has been included for visualization and characterization of the noncovalent interactions following the distribution of the critical points and bond paths. The existence of a bond critical point $(\mathrm{CP})$ and bond path connecting two atoms designate the interaction between those two atoms [62]. The hydrogen bonding interactions are characterized by the distribution of CPs and bond paths of the models used for compound (1) (see Figure 9). In Figure 9a, the hydrogen bonding interaction is characterized by the presence of a bond critical point that is represented by a red sphere and corresponding bond path between the hydrogen atom of the parent ring carbon atom and carbonyl oxygen atom of the partner molecule. The $\rho(\mathrm{r})$ value $(0.0109$ a.u. $)$ of the bond CP is also analyzed to verify the strength of the interaction. In the second model, the hydrogen bonding is characterized by the bond $\mathrm{CP}\left(\rho_{\mathrm{BCP}}=0.0068\right.$ a.u. $)$ and bond path connecting hydrogen atom of the pyridine ring and carbonyl oxygen atom. As discussed earlier (red dotted lines in Figure 7c), another 
interaction is evidenced by $\mathrm{CP}\left(\rho_{\mathrm{BCP}}=0.0060\right.$ a.u. $)$ and the corresponding bond path. Therefore, a ring $\mathrm{CP}$ is generated due to the formation of a ring motif and is represented by a yellow sphere.

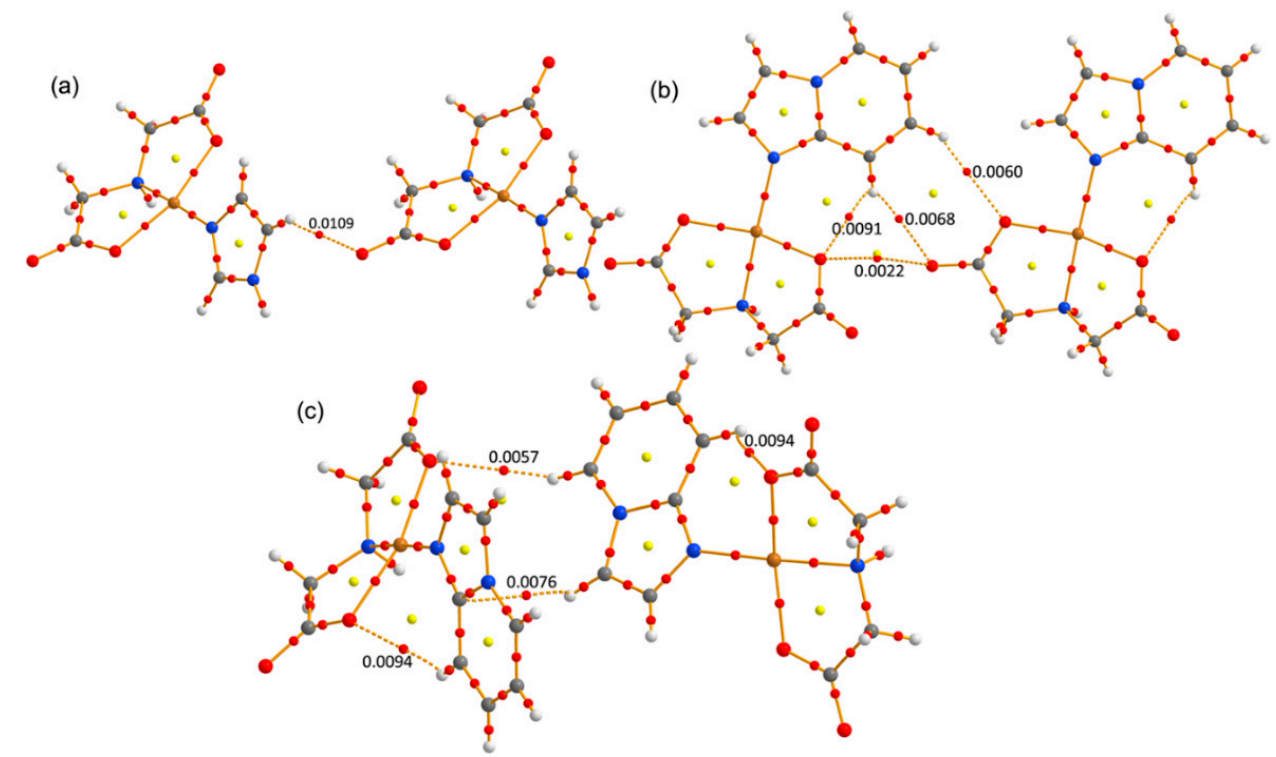

Figure 9. AIM analysis of different models $(\mathbf{a}-\mathbf{c})$. Red and yellow spheres represent bond and ring critical points, respectively. The bond paths connecting bond critical points are shown as dashed lines. The values of $\rho(\mathrm{r})$ at the bond critical points are given in atomic units (a.u.).

The intramolecular $\mathrm{C}-\mathrm{H} \cdots \mathrm{O}$ bonding and $\mathrm{O} \cdots \mathrm{O}$ contacts are also evidenced in AIM analysis and are characterized by the bond CPs, 0.0091 a.u and 0.0022 a.u, respectively (Figure $9 \mathrm{~b}$ ). The inspection of the results indicates that the values of $\rho(\mathrm{r})$ are larger in model 1 (0.0109 a.u.) than model 2 (0.0068 a.u.), in good agreement with the energetic analysis commented above. Furthermore, we analyzed the $\mathrm{C}-\mathrm{H} \cdots \pi$ interaction, depicted in Figure $9 \mathrm{c}$. The bond $\mathrm{CP}\left(\rho_{\mathrm{BCP}}=0.0076\right.$ a.u. $)$ and bond path connecting hydrogen atom of the imidazo ring carbon atom and carbon atom of the pyridine ring characterized the $\mathrm{C}-\mathrm{H} \cdots \pi$ interaction in (1). Finally, we further characterized the $\mathrm{C}-\mathrm{H} \cdots \pi$ interaction using the NCI index. The representation of NCI plot obtained for dimer that highlights the $\mathrm{C}-\mathrm{H} \cdots \pi$ interaction of compound (1) is shown in Figure 10. The $\pi$-facial noncovalent interaction involving the C-H donor of the ring carbon atoms is characterized by the extended green isosurface. The green isosurface has been identified over the rings of the imidazo[1,2-a]-pyridine ligand and directed towards the $\mathrm{C}-\mathrm{H}$ bond, thus characterizing the $\mathrm{C}-\mathrm{H} \cdots \pi$ interaction. Moreover, the small blue-green isosurfaces characterize the hydrogen bonding interactions in between ring carbon atoms and carboxylate oxygen atoms and are in agreement with the energetic study.

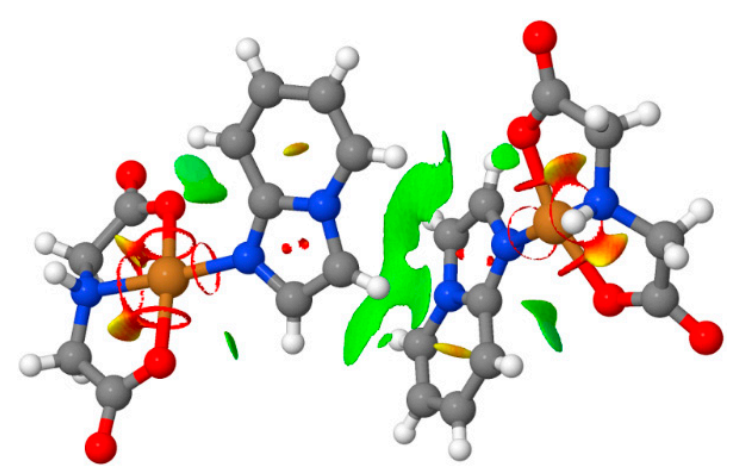

Figure 10. NCI plot of the self-assembled dimer in (1). The NCI plots only show the intermolecular interactions. 


\section{Conclusions}

In summary, the title polymeric compound reported herein exhibit $\mathrm{C}-\mathrm{H} \cdots \mathrm{O}$ and $\mathrm{C}-\mathrm{H} \cdots \pi$ interactions in the solid state that have been characterized using Hirshfeld surface and high-level theoretical calculation. Noncovalent interactions play a decisive role in building supramolecular self-assemblies that have been evaluated by DFT calculations, AIM and NCI plot analyses. The contribution of noncovalent interactions in the self-assembly process was estimated by providing individual energy values through computational studies. The results reported herein are expected to be useful to understand the solid-state structure of coordination polymers and have possible importance for research studies in supramolecular chemistry and crystal engineering.

Supplementary Materials: The following are available online at http:/ /www.mdpi.com/2073-4352/8/12/455/s1, One crystallographic file (CIF), CCDC-1868166; Table S1: Selected Bond-lengths $(\AA)$ and angles $\left({ }^{\circ}\right)$. Figures S1-S4: $\mathrm{N}-\mathrm{H}$-..O bonded motif; Decomposed fingerprint plots; Decomposed plots of $d_{\text {norm }}$ surface and PXRD.

Funding: This research received no external funding.

Conflicts of Interest: The author declares no conflict of interest. This research received no external funding and the Editor fully waived the APC since it was an invited article.

\section{References}

1. Furukawa, H.; Cordova, K.E.; O'Keeffe, M.; Yaghi, O.M. The Chemistry and Applications of Metal-Organic Frameworks. Science 2013, 341, 1230444. [CrossRef]

2. Zhou, H.-C.; Long, J.R.; Yaghi, O.M. Introduction to Metal-Organic Frameworks. Chem. Rev. 2012, 112, 673-674. [CrossRef] [PubMed]

3. Batten, S.R.; Champness, N.R.; Chen, X.-M.; Garcia-Martinez, J.; Kitagawa, S.; Ohrstrom, L.; O'Keeffe, M.; Suh, M.P.; Reedijk, J. Coordination polymers, metal-organic frameworks and the need for terminology guidelines. CrystEngComm 2012, 14, 3001-3004. [CrossRef]

4. Li, J.-R.; Sculley, J.; Zhou, H.-C. Metal-Organic Frameworks for Separations. Chem. Rev. 2012, 112, 869-932. [CrossRef] [PubMed]

5. Liu, J.; Thallapally, P.K.; McGrail, B.P.; Brown, D.R.; Liu, J. Progress in adsorption-based $\mathrm{CO}_{2}$ capture by metal-organic frameworks. Chem. Soc. Rev. 2012, 41, 2308-2322. [CrossRef]

6. He, H.; Song, Y.; Sun, F.; Bian, Z.; Gao, L.; Zhu, G. A porous metal-organic framework formed by a V-shaped ligand and $\mathrm{Zn}(\mathrm{II})$ ion with highly selective sensing for nitroaromatic explosives. J. Mater. Chem. A 2015, 3 , 16598-16603. [CrossRef]

7. Carlucci, L.; Ciani, G.; Proserpio, D.M.; Mitina, T.G.; Blatov, V.A. Entangled two-dimensional coordination networks: A general survey. Chem. Rev. 2014, 114, 7557-7580. [CrossRef]

8. Nagarkar, S.S.; Joarder, B.; Chaudhari, A.K.; Mukherjee, S.; Ghosh, S.K. Highly Selective Detection of Nitro Explosives by a Luminescent Metal-Organic Framework. Angew. Chem. Int. Ed. 2013, 52, 2881-2885. [CrossRef]

9. Liu, Y.-Y.; Wang, Z.-H.; Yang, J.; Liu, B.; Liu, Y.-Y.; Ma, J.-F. A series of coordination polymers based on reduced Schiff base multidentate anions and bis(imidazole) ligands: Syntheses, structures and photoluminescence. CrystEngComm 2011, 13, 3811-3821. [CrossRef]

10. Du, M.; Li, C.P.; Liu, C.S.; Fang, S.M. Design and construction of coordination polymers with mixed-ligand synthetic strategy. Coord. Chem. Rev. 2013, 257, 1282-1305. [CrossRef]

11. Li, M.-X.; Zhang, Y.-F.; He, X.; Shi, X.-M.; Wang, Y.-P.; Shao, M.; Wang, Z.-X. Diverse Structures and Ferro-/Ferri-/Antiferromagnetic Interactions of Pyridyltetrazole Coordination Polymers with Polycarboxylate Auxiliary Ligands. Cryst. Growth Des. 2016, 16, 2912-2922. [CrossRef]

12. Li, Y.-L.; Zhao, D.; Zhao, Y.; Wang, P.; Wang, H.-W.; Sun, W.-Y. Synthesis, structure, and magnetic and catalytic properties of metal frameworks with 2,2'-dinitro-4,4'-biphenyldicarboxylate and imidazole-containing tripodal ligands. Dalton Trans. 2016, 45, 8816-8823. [CrossRef] [PubMed]

13. Zhou, H.-C.; Kitagawa, S. Metal-Organic Frameworks (MOFs). Chem. Soc. Rev. 2014, 43, 5415-5418. [CrossRef] 
14. Amayuelas, E.; Fidalgo-Marijuan, A.; Barandika, G.; Bazán, B.; Urtiaga, M.K.; Arriortua, M.I. Mother structures related to the hexagonal and cubic close packing in $\mathrm{Cu}_{24}$ clusters: Solvent-influenced derivatives. CrystEngComm 2015, 17, 3297-3304. [CrossRef]

15. Du, M.; Li, C.-P.; Liu, C.-S.; Fang, S.-M. Design and construction of coordination polymers with mixed-ligand synthetic strategy. Chem. Rev. 2013, 257, 1282-1305.

16. Farrusseng, D. Metal-Organic Frameworks: Applications from Catalysis to Gas Storage, 1st ed.; Wiley-VCH: Weinheim, Germany, 2011.

17. Tranchemontagne, D.J.; Mendoza-Cortés, J.L.; O’Keeffe, M.; Yaghi, O.M. Secondary Building Units, Nets and Bonding in the Chemistry of Metal-Organic Frameworks. Chem. Soc. Rev. 2009, 38, 1257-1283. [CrossRef] [PubMed]

18. Erer, H.; Yesilel, O.Z.; Arıc1, M. A Series of Zinc(II) 3D $\rightarrow$ 3D Interpenetrated Coordination Polymers Based On Thiophene-2,5-dicarboxylate and Bis(Imidazole) Derivative Linkers. Cryst. Growth Des. 2015, 15, 3201-3211. [CrossRef]

19. Zhou, L.; Wang, C.; Zheng, X.; Tian, Z.; Wen, L.; Qu, H.; Li, D. New metal-organic frameworks based on 2,5-thiophenedicarboxylate and pyridine- or imidazole-based spacers: Syntheses, topological structures, and properties. Dalton Trans. 2013, 42, 16375-16386. [CrossRef]

20. Yaghi, O.M.; O'keeffe, M.; Ockwig, N.W.; Chae, H.K.; Eddaoudi, M.; Kim, J. Reticular synthesis and the design of new materials. Nature 2003, 423, 705-714. [CrossRef]

21. Mitra, M.; Manna, P.; Das, A.; Seth, S.K.; Helliwell, M.; Bauzá, A.; Choudhury, S.R.; Frontera, A.; Mukhopadhyay, S. On the Importance of Unprecedented Lone Pair-Salt Bridge Interactions in $\mathrm{Cu}(\mathrm{II})-$ Malonate-2-Amino-5-Chloropyridine-Perchlorate Ternary System. J. Phys. Chem. A 2013, 117, 5802-5811. [CrossRef]

22. Mitra, M.; Manna, P.; Seth, S.K.; Das, A.; Meredith, J.; Helliwell, M.; Bauzá, A.; Choudhury, S.R.; Frontera, A.; Mukhopadhyay, S. Salt-bridge $-\pi(\mathrm{sb}-\pi)$ interactions at work: Associative interactions of $\mathrm{sb}-\pi, \pi-\pi$ and anion- $\pi$ in $\mathrm{Cu}(\mathrm{II})$-malonate-2-aminopyridine-hexafluoridophosphate ternary system. CrystEngComm 2013, 15, 686-696. [CrossRef]

23. He, Y.C.; Yang, J.; Kan, W.Q.; Zhang, H.M.; Liu, Y.Y.; Ma, J.F. A New Microporous Anionic Metal-Organic Framework as a Platform for Highly Selective Adsorption and Separation of Organic Dyes. J. Mater. Chem. A 2015, 3, 1675-1681. [CrossRef]

24. Yan, W.; Han, L.J.; Jia, H.L.; Shen, K.; Wang, T.; Zheng, H.G. Three Highly Stable Cobalt MOFs Based on "Y"-Shaped Carboxylic Acid: Synthesis and Absorption of Anionic Dyes. Inorg. Chem. 2016, 55, 8816-8821. [CrossRef]

25. Seth, P.; Bauzá, A.; Frontera, A.; Massera, C.; Gamez, P.; Ghosh, A. Analysis of the contribution of the $\pi$-acidity of the s-tetrazine ring in the crystal packing of coordination polymers. CrystEngComm 2013, 15, 3031-3039. [CrossRef]

26. Seth, S.K. Exploration of supramolecular layer and bi-layer architecture in M(II)-PPP complexes: Structural elucidation and Hirshfeld surface analysis [PPP = 4-(3-Phenylpropyl)pyridine, $\mathrm{M}=\mathrm{Cu}(\mathrm{II}), \mathrm{Ni}(\mathrm{II})]$. J. Mol. Struct. 2014, 1070, 65-74. [CrossRef]

27. Maity, T.; Mandal, H.; Bauza, A.; Samanta, B.C.; Frontera, A.; Seth, S.K. Quantifying conventional $\mathrm{C}-\mathrm{H} \cdots \pi($ aryl $)$ and unconventional $\mathrm{C}-\mathrm{H} \cdots \pi$ (chelate) interactions in dinuclear $\mathrm{Cu}(\mathrm{II})$ complexes: Experimental observations, Hirshfeld surface and theoretical DFT study. New J. Chem. 2018, 42, 10202-10213. [CrossRef]

28. Bloom, J.W.G.; Wheeler, S.E. Taking the Aromaticity out of Aromatic Interactions. Angew. Chem. Int. Ed. 2011, 50, 7847-7849. [CrossRef]

29. Seth, S.K.; Sarkar, D.; Kar, T. Use of $\pi-\pi$ forces to steer the assembly of chromone derivatives into hydrogen bonded supramolecular layers: Crystal structures and Hirshfeld surface analyses. CrystEngComm 2011, 13, 4528-4535. [CrossRef]

30. Seth, S.K.; Manna, P.; Singh, N.J.; Mitra, M.; Jana, A.D.; Das, A.D.; Choudhury, S.R.; Kar, T.; Mukhopadhyay, S.; Kim, K.S. Molecular architecture using novel types of noncovalent $\pi$-interactions involving aromatic neutrals, aromatic cations and $\pi$-anions. CrystEngComm 2013, 15, 1285-1288. [CrossRef]

31. Manna, P.; Seth, S.K.; Mitra, M.; Das, A.; Singh, N.J.; Choudhury, S.R.; Kar, T.; Mukhopadhyay, S. A successive layer-by-layer assembly of supramolecular frameworks driven by a novel type of face-to-face $\pi^{+}-\pi^{+}$interactions. CrystEngComm 2013, 15, 7879-7886. [CrossRef] 
32. Frontera, A.; Gamez, P.; Mascal, M.; Mooibroek, T.J.; Reedijk, J. Putting Anion- $\pi$ Interactions into Perspective. Angew. Chem. Int. Ed. 2011, 50, 9564-9583. [CrossRef] [PubMed]

33. Manna, P.; Seth, S.K.; Mitra, M.; Choudhury, S.R.; Bauzá, A.; Frontera, A.; Mukhopadhyay, S. Experimental and Computational Study of Counterintuitive $\mathrm{ClO}_{4}{ }^{-} \ldots \mathrm{ClO}_{4}{ }^{-}$Interactions and the Interplay between $\pi^{+} \ldots \pi$ and Anion $\cdots \pi^{+}$Interactions. Cryst. Growth Des. 2014, 14, 5812-5821. [CrossRef]

34. Manna, P.; Seth, S.K.; Bauzá, A.; Mitra, M.; Choudhury, S.R.; Frontera, A.; Mukhopadhyay, S. pH Dependent Formation of Unprecedented Water-Bromide Cluster in the Bromide Salts of PTP Assisted by Anion $\cdots \pi$ Interactions: Synthesis, Structure, and DFT Study. Cryst. Growth Des. 2014, 14, 747-755. [CrossRef]

35. Mitra, M.; Manna, P.; Bauzá, A.; Ballester, P.; Seth, S.K.; Choudhury, S.R.; Frontera, A.; Mukhopadhyay, S. 3-Picoline Mediated Self-Assembly of $\mathrm{M}(\mathrm{II})-$ Malonate Complexes ( $\mathrm{M}=\mathrm{Ni} / \mathrm{Co} / \mathrm{Mn} / \mathrm{Mg} / \mathrm{Zn} / \mathrm{Cu})$ Assisted by VariousWeak Forces Involving Lone Pair $\cdots \pi, \pi-\pi$, and Anion $\cdots \pi-$ Hole Interactions. J. Phys. Chem. B 2014, 118, 14713-14726. [CrossRef] [PubMed]

36. Seth, S.K.; Saha, I.; Estarellas, C.; Frontera, A.; Kar, T.; Mukhopadhyay, S. Supramolecular Self-Assembly of M-IDA Complexes Involving Lone-Pair $\cdots \pi$ Interactions: Crystal Structures, Hirshfeld Surface Analysis, and DFT Calculations [H2IDA = iminodiacetic acid, $\mathrm{M}=\mathrm{Cu}(\mathrm{II}), \mathrm{Ni}(\mathrm{II})$ ]. Cryst. Growth Des. 2011, 11, 3250-3265. [CrossRef]

37. Manna, P.; Seth, S.K.; Das, A.; Hemming, J.; Prendergast, R.; Helliwell, M.; Choudhury, S.R.; Frontera, A.; Mukhopadhyay, S. Anion Induced Formation of Supramolecular Associations Involving Lone pair $\cdots \pi$ and Anion $\cdots \pi$ Interactions in Co(II) Malonate Complexes: Experimental Observations, Hirshfeld Surface Analyses and DFT Studies. Inorg. Chem. 2012, 51, 3557-3571. [CrossRef]

38. Steed, J.W.; Turner, D.R.; Wallace, K.J. Core Concepts in Supramolecular Chemistry and Nanochemistry; John Wiley \& Sons, Ltd.: Chichester, UK, 2007; pp. 194-228.

39. Bruker. SAINT, Version 6.36a; Bruker-AXS Inc.: Madison, WI, USA, 2002.

40. Bruker. SMART, Version 5.625 and SADABS, Version 2.03a; Bruker AXS Inc.: Madison, WI, USA, 2001.

41. Sheldrick, G.M. A short history of SHELX. Acta Crystallogr. A 2008, 64, 112-122. [CrossRef]

42. Sheldrick, G.M. Crystal structure refinement with SHELXL. Acta Crystallogr. C 2015, 71, 3-8. [CrossRef] [PubMed]

43. Farrugia, L.J. WinGX suit for small-molecule single-crystal crystallography. J. Appl. Crystallogr. 1999, 32, 837-838. [CrossRef]

44. Spek, A.L. Single-crystal structure validation with the program PLATON. J. Appl. Crystallogr. 2003, 36, 7-13. [CrossRef]

45. Spackman, M.A.; McKinnon, J.J. Fingerprinting intermolecular interactions in molecular crystals. CrystEngComm 2002, 4, 378-392. [CrossRef]

46. McKinnon, J.J.; Jayatilaka, D.; Spackman, M.A. Towards quantitative analysis of intermolecular interactions with Hirshfeld surfaces. Chem. Commun. 2007, 37, 3814-3816. [CrossRef]

47. Seth, S.K.; Bauzá, A.; Frontera, A. Screening polymorphism in a NiIJII) metal-organic framework: Experimental observations, Hirshfeld surface analyses and DFT studies. CrystEngComm 2018, 20, 746-754. [CrossRef]

48. Seth, S.K. Structural characterization and Hirshfeld surface analysis of a CoII complex with imidazo[1,2-a]-pyridine. Acta Crystallogr. E 2018, 74, 600-606. [CrossRef] [PubMed]

49. Seth, S.K.; Bauzá, A.; Mahmoudi, G.; Stilinović, V.; López-Torres, E.; Zaragoza, G.; Keramidas, A.D.; Frontera, A. On the importance of $\mathrm{Pb} \cdots \mathrm{X}(\mathrm{X}=\mathrm{O}, \mathrm{N}, \mathrm{S}, \mathrm{Br})$ tetrel bonding interactions in a series of tetraand hexa-coordinated $\mathrm{Pb}(\mathrm{II})$ compounds. CrystEngComm 2018, 20, 5033-5044. [CrossRef]

50. Spackman, M.A.; Byrom, P.G. A novel definition of a molecule in a crystal. Chem. Phys. Lett. 1997, 267, 215-220. [CrossRef]

51. McKinnon, J.J.; Mitchell, A.S.; Spackman, M.A. Hirshfeld Surfaces: A New Tool for Visualising and Exploring Molecular Crystals. Chem. Eur. J. 1998, 4, 2136-2141. [CrossRef]

52. McKinnon, J.J.; Spackman, M.A.; Mitchell, A.S. Novel tools for visualizing and exploring intermolecular interactions in molecular crystals. Acta Crystallogr. B 2004, 60, 627-668. [CrossRef]

53. Rohl, A.L.; Moret, M.; Kaminsky, W.; Claborn, K.; Mckinnon, J.J.; Kahr, B. Hirshfeld Surfaces Identify Inadequacies in Computations of Intermolecular Interactions in Crystals: Pentamorphic 1,8-Dihydroxyanthraquinone. Cryst. Growth Des. 2008, 8, 4517-4525. [CrossRef] 
54. Seth, S.K.; Sarkar, D.; Roy, A.; Kar, T. Insight into supramolecular self-assembly directed by weak interactions in acetophenone derivatives: Crystal structures and Hirshfeld surface analyses. CrystEngComm 2011, 13, 6728-6741. [CrossRef]

55. Seth, S.K.; Sarkar, D.; Jana, A.D.; Kar, T. On the Possibility of Tuning Molecular Edges To Direct Supramolecular Self-Assembly in Coumarin Derivatives through Cooperative Weak Forces: Crystallographic and Hirshfeld Surface Analyses. Cryst. Growth Des. 2011, 11, 4837-4849. [CrossRef]

56. Seth, S.K. Structural elucidation and contribution of intermolecular interactions in O-hydroxy acyl aromatics: Insights from X-ray and Hirshfeld surface analysis. J. Mol. Struct. 2014, 1064, 70-75. [CrossRef]

57. Wolff, S.K.; Grimwood, D.J.; McKinnon, J.J.; Jayatilaka, D.; Spackman, M.A. CrystalExplorer 3.1; University of Western Australia: Perth, Australia, 2007.

58. Frisch, M.J.; Trucks, G.W.; Schlegel, H.B.; Scuseria, G.E.; Robb, M.A.; Cheeseman, J.R.; Scalmani, G.; Barone, V.; Petersson, G.A.; Nakatsuji, H.; et al. Gaussian 09, Revision C.01; Gaussian, Inc.: Wallingford, CT, USA, 2009.

59. Nisa, R.U.; Ayub, K. Mechanism of Zn(OTf $)_{2}$ catalyzed hydroamination-hydrogenation of alkynes with amines: Insight from theory. New J. Chem. 2017, 41, 5082-5090. [CrossRef]

60. Mahmood, T.; Kosar, N.; Ayub, K. DFT study of acceleration of electrocyclization in photochromes under radical cationic conditions: Comparison with recent experimental data. Tetrahedron 2017, 73, 3521-3528. [CrossRef]

61. Bibi, S.; Ullah, H.; Ahmad, S.M.; Ali Shah, A.-U.-H.; Bilal, S.; Tahir, A.A.; Ayub, K. Molecular and electronic structure elucidation of polypyrrole gas sensors. Phys. Chem. C 2015, 119, 15994-16003. [CrossRef]

62. Bader, R.F.W. A quantum theory of molecular structure and its applications. Chem. Rev. 1991, 91, 893-928. [CrossRef]

63. Keith, T.A. AIMAll, Version 13.05.06; TK Gristmill Software: Overland Park, KS, USA, 2013.

64. Bader, R.F.W. Atoms in Molecules, a Quantum Theory; Oxford University Press: New York, NY, USA, 1990.

65. Contreras-García, J.; Johnson, E.R.; Keinan, S.; Chaudret, R.; Piquemal, J.-P.; Beratan, D.N.; Yang, W. NCIPLOT: A Program for Plotting Noncovalent Interaction Regions. J. Chem. Theory Comput. 2011, 7, 625-632. [CrossRef] [PubMed]

66. Hathaway, B.J.; Wilkinson, G.; Gillard, R.D.; McCleverty, J.A. (Eds.) Comprehensive Coordination Chemistry; Pergamon Press: Oxford, UK, 1987; Volume 5, Chapter 53, p. 612.

67. Castiñeiras Campos, A.; Busnot, A.; Abarca García, M.E.; Sicilia Zafra, A.G.; González Pérez, J.M.; Niclós Gutiérrez, J. Mixed-ligand copper(II) complexes with iminodiacetato and 2- or 4-methylimidazole: Molecular and crystal structure of the 'remote' isomer iminodiacetato(5-methylimidazole)copper(II) monohydrate, [Cu(IDA)(5MeImH)] $\cdot \mathrm{H}_{2}$ O. Inorg. Chim. Acta 1994, 215, 73-78. [CrossRef]

68. Castiñeiras Campos, A.; Sicilia Zafra, A.G.; González Pérez, J.M.; Niclós Gutiérrez, J.; Chinea, E.; Mederos, A. Mixed-ligand copper(II) complexes with N-methyl derivatives of iminodiacetato or imidazole: Crystal structures of ( $\mathrm{N}$-methyliminodiacetato) (imidazole) copper(II), [Cu(MIDA) (ImH)] and diaqua (iminodiacetato) ( $\mathrm{N}$-methyl-imidazole) copper(II) monohydrate, $\left[\mathrm{Cu}(\mathrm{IDA})(1 \mathrm{MelmH})\left(\mathrm{H}_{2} \mathrm{O}\right)_{2}\right] \cdot \mathrm{H}_{2} \mathrm{O}$. Inorg. Chim. Acta 1996, 241, 39-45.

69. Castiñeiras, A.; Tercero, J.M.; Matilla, A.; González, J.M.; Sicilia, A.G.; Niclós, J. Structures and properties of copper(II) complexes with iminodiacetato and imidazole or related ligands. I. crystal structure of aqua(imidazole)(iminodiaceato)copper(II) monohydrate and (imidazole)( $N$-carboxymethyl-D,LThreoninato)copper(II). J. Coord. Chem. 1995, 35, 61-72. [CrossRef]

70. Dung, N.H.; Viossat, B.; Busnot, A.; González Pérez, J.M.; Niclós Gutiérrez, J.; Gardette, F. Additional contribution to the study of iminodiacetate (IDA) and imidazole (ImH) mixed-ligand copper(II) complexes; crystal structure of $\left[\mathrm{Cu}(\mathrm{IDA})(\mathrm{ImH})\left(\mathrm{CH}_{3} \mathrm{OH}\right)\right] \cdot 0.37 \mathrm{H}_{2} \mathrm{O}$. Inorg. Chim. Acta 1990, 174, 145-148.

(C) 2018 by the author. Licensee MDPI, Basel, Switzerland. This article is an open access article distributed under the terms and conditions of the Creative Commons Attribution (CC BY) license (http://creativecommons.org/licenses/by/4.0/). 